\title{
Carbon Monoxide Poisoning: The Culture of Indoor Burning
}

\author{
John Quinn'1, Tomas Zeleny' ${ }^{2}$, Vladimir Bencko ${ }^{3}$ \\ ${ }^{1}$ Charles University in Prague, First Faculty of Medicine, Institute of Hygiene and Epidemiology, Prague Center \\ for Global Health, Prague, Czech Republic \\ ${ }^{2}$ Charles University in Prague, Faculty of Social Sciences, First Faculty of Medicine, Institute of Economic Studies, \\ Institute of Hygiene and Epidemiology, Prague, Czech Republic \\ ${ }^{3}$ Charles University in Prague, First Faculty of Medicine, Institute of Hygiene and Epidemiology, Prague, \\ Czech Republic \\ Email: john.quinn@If1.cuni.cz, zeleny.t@gmail.com, Vladimir.bencko@lf1.cuni.cz
}

Received 8 June 2014; revised 7 July 2014; accepted 6 August 2014

Copyright () 2014 by authors and Scientific Research Publishing Inc.

This work is licensed under the Creative Commons Attribution International License (CC BY).

http://creativecommons.org/licenses/by/4.0/

(c) (i) Open Access

\begin{abstract}
This patient case report describes a 40-year-old African woman presenting with a classic acute presentation of carbon monoxide poisoning from an unlikely source responding to conventional treatment. This case highlights the classic presenting features of carbon monoxide poisoning and the requirement to maintain a high index of suspicion and immediate use of rapid empirical treatment in the undifferentiated patient, sometimes before diagnostics and definitive diagnosis can be determined. The definitive diagnosis and cause of poisoning are also discussed to educate the emergency physician to new and foreign cultural habits and encourage best medical practices within multicultural societies.
\end{abstract}

\section{Keywords}

Carbon Monoxide Poisoning, Indoor Burning, Carboxyhemoglobin

\section{Introduction}

A 40-year-old Ethiopian female presents to the emergency department with acute nausea and vomiting, mild confusion to time and place, a 9/10 pain scale global headache and new onset visual disturbance, cherry red forehead and cheeks, shortness of breath and unremitting chest palpitations. She states that she is allergic to an unknown antibiotic she was given a few months ago for an uncomplicated urinary tract infection (UTI), and that she is a non-smoker and denies any significant medical history to which she is followed for and denies previous 
surgery or invasive medical treatment. She denies taking any new medicines, alcohol or recreational drugs in the past 72 hours. She presents with her partner who has just picked the patient up from a cultural gathering where an unknown burning source and fire may have been used inside the home for roughly 3.5 hours.

Vital signs at triage and presentation (Table 1).

Upon triage nurse encounter, 15 liters high flow oxygen is begun via non-rebreather mask with a portable oxygen container and a standard blood work-up obtained (full blood count, urea, electrolytes and creatinine and coagulation studies). The ECG performed in triage was unremarkable and showed a sinus tachycardia without abnormality. The urinalysis carried out revealed no abnormal findings and was sent for pregnancy testing, which was negative. In approximately 1 hour 45 minutes later, the first physician encounter occurs with the patient being still in triage.

\section{Medical Case Work-Up and Treatment}

Upon history or present illness and physical exam by physician, the patient is supine on a triage bench. The patient states she is nauseous, dizzy, and lightheaded, has memory loss of the afternoon, is lethargic and in mild respiratory distress with increased work of breathing. Physical exam reveals cherry red cheeks and forehead, pupils are equal and reactive to light and accommodation (PEARLA), ear, nose and throat and exam (ENT) is unremarkable, lung sounds are clear and equal bilaterally, $S_{1}$ and $S_{2}$ heart sounds are heard and normal with no rubs, gallops or murmurs. The abdomen is soft and non-tender, negative Murphy's sign, no masses and no hernia noted; bowel sounds are heard throughout the abdomen without any complaint. Upper and lower extremity exam is remarkable only to a decrease in power bilaterally to the upper and lower limbs with pulse, motor and sensory intact at periphery.

The plan after physical exam are to review the routine bloods, obtain an arterial blood gas (ABG), study the electrocardiogram (ECG), confirm pregnancy status and urinalysis and continue oxygen therapy empirically.

An arterial blood gas is taken with the following values moments later in Table 2.

The first ABG taken after initial treatment commenced reveals respiratory distress with low $\mathrm{pO}_{2}$ and carboxyhemoglobinemia.

The patient was admitted to the Clinical Decision Unit (CDU) of the emergency department for observation and further oxygen therapy, antiemetic and headache pain management with paracetamol and ondansetron. The patient rested comfortably in the CDU and was compliant with all medication and treatment. Clinical observations were recorded hourly to include vital signs and GCS.

Upon the physician four-hour follow-up with 15 liters non-rebreather oxygen therapy, the patients cherry red presenting features had cleared, all symptoms of nausea, vomiting and headache had resolved and the retrograde amnesia had resolved. The follow-up arterial blood gas listed in Table 3.

The second ABG reveals a complete reversal and correction of $\mathrm{pO}_{2}$ and carboxyhemoglobinemia. With resolution of chief complaints, and no residual signs or symptoms of illness, a discharge plan was created with follow-up

Table 1. Presenting vital signs.

\begin{tabular}{ccccc}
\hline $\mathrm{HR}$ & $\mathrm{SaO}_{2}$ & $\mathrm{BP}$ & $\mathrm{GCS}$ & $\mathrm{RR}$ \\
\hline 122 & $90 \%$ & $192 / 79$ & $14_{\mathrm{E}=4, \mathrm{~V}=4, \mathrm{M}=6}$ \\
\hline
\end{tabular}

Table 2. First ABG.

\begin{tabular}{cc}
\hline $\mathrm{pH}$ & 7.41 \\
$\mathrm{pCO}_{2}$ & $5.2 \mathrm{kPa}$ \\
$\mathrm{pO}_{2}$ & $6.3 \mathrm{kPa}(\downarrow)$ \\
$\mathrm{Na}^{+}$ & $138 \mathrm{mmol} / \mathrm{L}$ \\
$\mathrm{K}^{+}$ & $3.4 \mathrm{mmol} / \mathrm{L}$ \\
$\mathrm{Lactate}$ & 0.9 \\
$\mathrm{COHb}$ & $8.4 \%(\uparrow)$ \\
$\mathrm{sO}_{2}$ & $89.6 \%(\downarrow)$ \\
$\mathrm{BEecf}$ & $0.1 \mathrm{mmol} / \mathrm{L}$ \\
$\mathrm{sO}_{2}(\mathrm{c})$ & $83.0 \%$ \\
$\mathrm{HCO}_{3}^{-}$ & $24.7 \mathrm{mmol} / \mathrm{L}$ \\
\hline
\end{tabular}


Table 3. Second ABG.

\begin{tabular}{cc}
\hline $\mathrm{pH}$ & 7.41 \\
$\mathrm{pCO}_{2}$ & $5.2 \mathrm{kPa}$ \\
$\mathrm{pO}_{2}$ & $16.0 \mathrm{kPa}$ \\
$\mathrm{Na}^{+}$ & $137 \mathrm{mmol} / \mathrm{L}$ \\
$\mathrm{K}^{+}$ & $3.5 \mathrm{mmol} / \mathrm{L}$ \\
Lactate & 0.5 \\
$\mathrm{COHb}$ & $0.6 \%$ \\
$\mathrm{sO}_{2}$ & $99.3 \%$ \\
$\mathrm{BEecf}$ & $-0.5 \mathrm{mmol} / \mathrm{L}$ \\
$\mathrm{sO}_{2(\mathrm{c})}$ & $98.7 \%$ \\
$\mathrm{HCO}_{3}^{-}$ & $24.1 \mathrm{mmol} / \mathrm{L}$ \\
\hline
\end{tabular}

to the patients' General Practitioner (GP) and for the patient to return if signs and symptoms got worse or changed. The patients' partner was willing to observe the patient in the home. An educational awareness plan was put together to review incomplete combustion in the home with various fuels when in closed quarters without adequate ventilation. The patient's vital signs upon discharge were as follows in Table 4.

\section{Discussion}

Undifferentiated patient presentations to Level One Trauma Center, Regional and Resource level facilities are increasing throughout Europe, North America and Australasia. Globalization has increased migration across borders and has lead to a large mix and multicultural patient populations across countries and emergency departments. Many of such cultures may not be understood or completely appreciated by local physicians as to living details and traditional cultural practices. As emergency departments see an ever-growing number of patients across the lifespan spectrum and from a myriad of cultural and socioeconomic backgrounds, it is imperative that ethnic understanding be highlighted to improve and engender best practices in patient care and disease prevention.

In this case, an Ethiopian cook pot used for feast days was used in an exclusive indoor environment in cold and wet northern Europe for 3.5 hours. The family and friends using this device where not educated about incomplete combustion and the requirement of ventilation when burning fossil fuels as its use in Ethiopia do not require or have a hermetically sealed indoor environment when in use. Other members participating in this cultural event also fell ill and presented to other healthcare facilitates but were not followed for this case study. Indoor air pollution and global health is a significant contributor to morbidity and mortality.

Over 3 billion people cook and heat their homes using open fires and leaky stoves using biomass and coal and nearly 2 million people die prematurely from non-communicable and preventable illnesses attributable to a reduction in indoor air quality [1]. Excessive use of biomass and coal can lead to pneumonia, chronic obstructive pulmonary disease and, in the acute setting, death from carbon monoxide poisoning.

\section{Conclusions}

The undifferentiated patient requires a standardized approach and when in acute distress, requires immediate treatment in the absence of a clear diagnosis when history may not be forthcoming or otherwise definitively known. Carbon monoxide poisoning can present clinically with cherry red discoloration to the face and skin and with symptomology of nausea, vomiting and a decreased level of consciousness. Recent history of exposure to incomplete combustion or other indoor burning of various fuels should direct a high index of suspicion to carbon monoxide poisoning with an index of suspicion in the multicultural society.

\section{Disclosures}

This paper was in part funded by a grant by Institute of Economic Studies, Faculty of Social Sciences, Charles University in Prague. This paper is dedicated to GAUK 910892. 
Table 4. Discharge vital signs.

\begin{tabular}{ccccc}
\hline $\mathrm{HR}$ & $\mathrm{SaO}_{2}$ & $\mathrm{BP}$ & $\mathrm{GCS}$ & $\mathrm{RR}$ \\
\hline 69 & $100 \%$ & $98 / 66$ & $15_{\mathrm{E}=4, \mathrm{~V}=5, \mathrm{M}=6}$ & 14 \\
\hline
\end{tabular}

\section{Authors' Contributions}

JQ performed the patient assessment and examination and was the main contributor in writing of the manuscript. TZ and VB analyzed and interpreted the patient data and provided overall synthesis of the case presentation. All authors read and approved the final manuscript.

\section{References}

[1] Taylor, W. (2010) The Burden of Non-Communicable Diseases in India. Cameron Institute, October 10. 
Scientific Research Publishing (SCIRP) is one of the largest Open Access journal publishers. It is currently publishing more than 200 open access, online, peer-reviewed journals covering a wide range of academic disciplines. SCIRP serves the worldwide academic communities and contributes to the progress and application of science with its publication.

Other selected journals from SCIRP are listed as below. Submit your manuscript to us via either submit@scirp.org or Online Submission Portal.
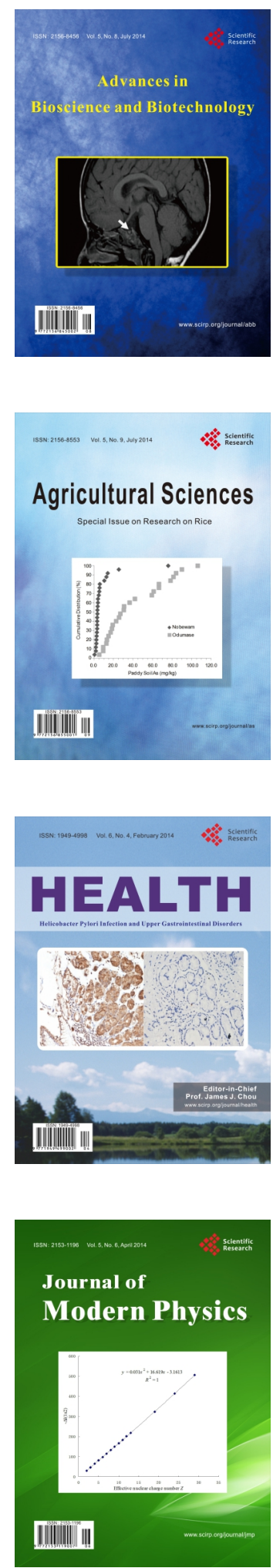
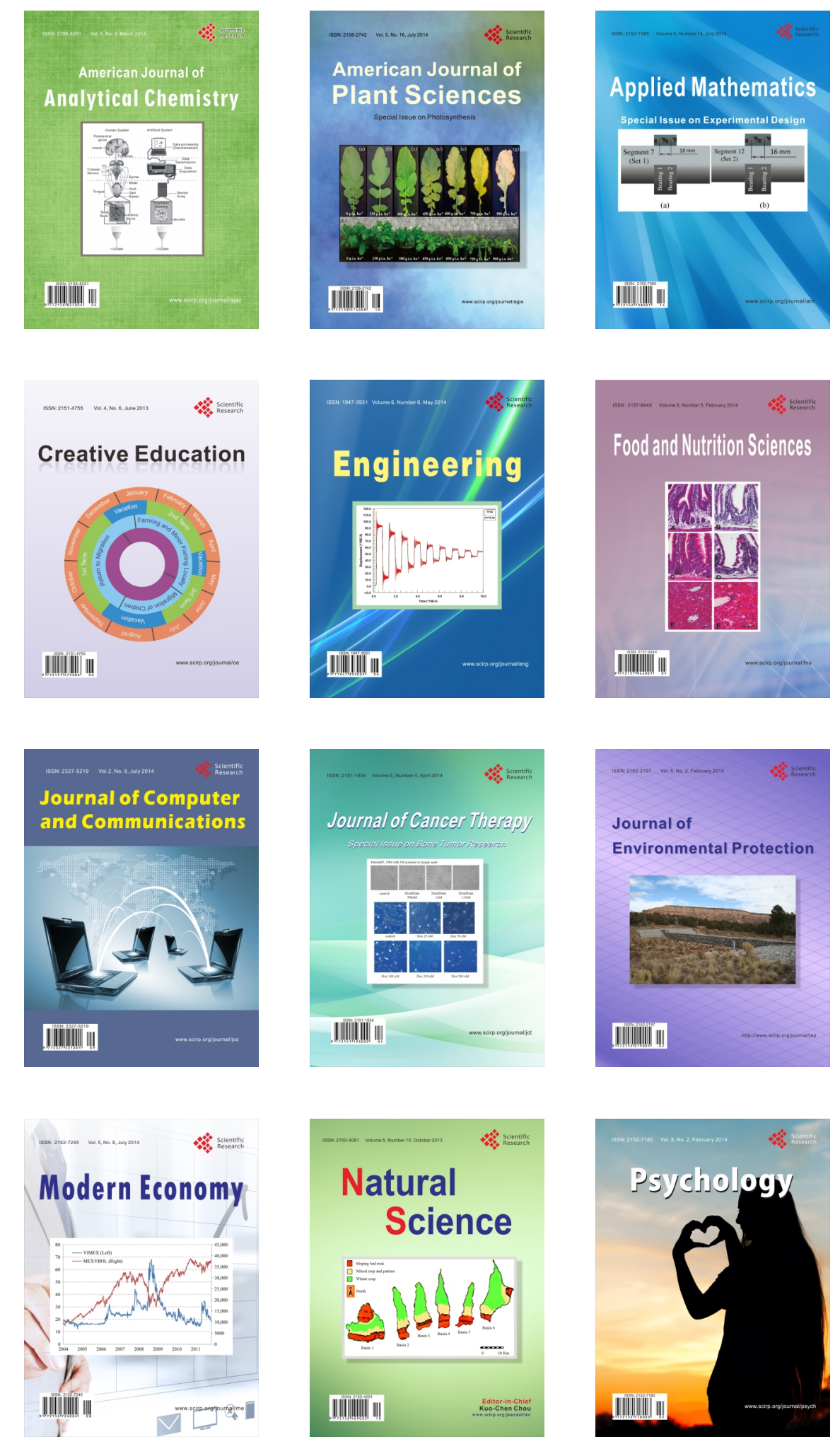